\title{
The pattern of congenital heart defects arising from reduced Tbx5 expression is altered in a Down syndrome mouse model
}

Renita C. Polk ${ }^{1,2}$, Peter Gergics ${ }^{4}$, Jeffrey D. Steimle ${ }^{3}$, Huiqing Li ${ }^{1}$, Ivan P. Moskowitz ${ }^{3}$, Sally A. Camper ${ }^{4}$ and Roger H. Reeves ${ }^{1,2^{*}}$

\begin{abstract}
Background: Nearly half of all individuals with Down Syndrome (DS) have some type of congenital heart defect (CHD), suggesting that DS sensitizes to CHD but does not cause it. We used a common mouse model of DS, the Ts65Dn mouse, to study the contribution of Tbx5, a known modifier of CHD, to heart defects on a trisomic backgroun. Mice that were heterozygous for a Tbx5 null allele were crossed with Ts65Dn mice. Thoraxes of progeny were fixed in 10\% formalin, embedded in paraffin, and sectioned for analysis of CHD. Gene expression in embryonic hearts was examined by quantitative PCR and in situ hybridization. A TBX5 DNA binding site was verified by luciferase assays.
\end{abstract}

Methods: Mice that were heterozygous for a Tbx5 null allele were crossed with Ts65Dn mice. Thoraxes of progeny were fixed in $10 \%$ formalin, embedded in paraffin, and sectioned for analysis of CHD. Gene expression in embryonic hearts was examined by quantitative PCR and in situ hybridization. A TBX5 DNA binding site was verified by luciferase assays.

Results: We crossed mice that were heterozygous for a Tbx5 null allele with Ts65Dn mice. Mice that were trisomic and carried the Tbx5 mutation (Ts65Dn;Tbx $5^{+/-}$) had a significantly increased incidence of overriding aorta compared to their euploid littermates. Ts65Dn;Tbx $5^{+/-}$mice also showed reduced expression of Pit $\times 2$, a molecular marker for the left atrium. Transcript levels of the trisomic Adamts 1 gene were decreased in $\mathrm{Tb}_{\mathrm{C}} \mathrm{5}^{+/-}$mice compared to their euploid littermates. Evidence of a valid binding site for TBX5 upstream of the trisomic Adamts 1 locus was also shown.

Conclusion: Haploinsufficiency of Tbx5 and trisomy affects alignment of the aorta and this effect may stem from deviations from normal left-right patterning in the heart. We have unveiled a previously unknown interaction between the Tbx5 gene and trisomy, suggesting a connection between Tbx5 and trisomic genes important during heart development.

Keywords: Heart development, Congenital heart defect, Down syndrome, Trisomy

\footnotetext{
* Correspondence: rreeves@jhmi.edu

${ }^{1}$ Department of Physiology at Johns Hopkins, Biophysics 201, 725 N. Wolfe

St., Baltimore, MD 21205, USA

${ }^{2}$ McKusick Nathans Institute for Genetic Medicine, School of Medicine, Johns

Hopkins University, Baltimore, MD, USA

Full list of author information is available at the end of the article
} 


\section{Background}

Congenital heart defects (CHD) comprise the most common congenital anomaly in live births [1]. There is an especially high incidence of CHD in Down syndrome (DS) as $40-50 \%$ of individuals with trisomy for human chromosome 21 (Hsa21) are affected [2-7]. In particular, atrioventricular septal defect (AVSD) occurs in about $20 \%$ of people with DS, a frequency about 2000-fold higher than in the population at large [8]. Since half of those with DS have a normal heart, additional genetic and environmental factors must interact with DS to cause CHD. Thus, dosage effects of Hsa21 genes comprise a complex modifier that, in conjunction with other risk factors such as single-gene variants, alters outcomes of heart development. Trisomy can be thought of as a genetically sensitizing condition that de-stabilizes normal heart development, unveiling roles of disomic modifiers of CHD [8, 9]. Attempts to identify genes predisposing to CHD in DS have understandably focused on Hsa21, while there has been little consideration of disomic modifiers that may contribute to this increased risk.

We consider the role of $T b x 5$, a known contributor to heart development, as a modifier and assess its interaction with trisomy. Tbx5, a transcription factor, has well-described effects in cardiac and limb development $[10,11]$. Mutations in this gene are associated with Holt-Oram syndrome and about $85 \%$ of affected individuals have a structural heart defect and/or abnormalities in the cardiac conduction system. Holt-Oram patients most often present with atrial septal defects (ASDs) and ventricular septal defects (VSDs) [12]. Tbx5 has a well-studied role in the morphogenesis of the four heart chambers. It is expressed in the left ventricle (LV) and both atria during chamber maturation and septation [13]. Ectopic expression in the right ventricle (RV), or deletion of $T b x 5$ in the left ventricles (LV) of mice suppresses formation of the ventricular septum, resulting in formation of a single ventricle [14]. Its importance in heart development suggests that variants affecting $T b x 5$ expression might affect heart development on the "sensitized" trisomic background.

Animal models provide important information for understanding the pathogenesis of $\mathrm{CHD}$ and the molecular mechanisms that give rise to these conditions. Orthologs of many genes on Hsa21 are found on mouse chromosome 16 (Mmu16), with smaller subsets on Mmu10 and Mmu17 [15]. The most widely studied DS mouse model, Ts65Dn, is trisomic for a segment of Mmu16 containing about half of the mouse genes orthologous to Hsa21 [16]. The freely segregating extra chromosome carrying these genes also contains genes from Mmu17 that are not conserved with Hsa21, thus this is not an exact model $[17,18]$. Ts65Dn mice display a number of the features of DS, including cardiac abnormalities, although these occur at a lower frequency than in people with DS $[9,19]$. Our lab has previously identified the Creld 1 and Hey 2 genes as disomic modifiers of septal development on this trisomic background [9]. Haploinsufficiency for either of these disomic modifiers alone did not affect heart development, but on a trisomic background the frequency of maldevelopment was increased significantly. The Ts65Dn model thus sensitizes heart development to other genetic perturbations. We used the Ts65Dn mouse model here to examine the role of $T b x 5$ in heart development.

A mouse model with a null allele for $T b \times 5$ has been described [20]. Homozygous null $T b x 5^{-1-}$ embryos (Black Swiss/SvJ background) die by embryonic day 10.5 (E10.5) and lack cardiac looping and endocardial cushion formation, among other severe defects [20]. The viability of and defects observed in $T b \times 5^{+/-}$mice are greatly influenced by genetic background. Bruneau et al. report a $10 \%$ frequency of the $T b \times 5$ null allele on a 129SvEv/129SvJ background at birth and $28 \%$ on a Black Swiss/129SvJ background, instead of the expected Mendelian ratio of $50 \%$. Deviation from the expected frequency indicates that prenatal loss has occurred; the different frequencies in different mouse strains suggest that genetic background contributes to the penetrance and expressivity of heart phenotypes in this situation [20]. Therefore, the effects of $T b x 5$ dosage are susceptible to additional genetic modifiers. The molecular mechanisms by which $T b \times 5$ influences heart development are incompletely described and possible interactions between $T b x 5$ and genes on Hsa21 are unknown. We hypothesize that Tbx5 acts as a genetic modifier to alter CHD in Ts65Dn mice. Here we provide evidence of an interaction between Tbx5 and trisomy and the effects of that interaction on trisomic gene expression and left-right patterning of the heart.

\section{Results \\ Viability of $\mathrm{Tb} \times 5^{+/-}$mice is dependent on genetic background}

Crosses between B6.Tbx $5^{+/-}$male mice and B6C3.Ts65Dn females were established to examine the role of $T b x 5$ as a

\begin{tabular}{ll} 
Table 1 Strain dependent viability of euploid $\mathrm{Tb} \times 5^{+/-}$mice at \\
weaning & \\
\hline Genetic background & $11 \%(n=591)$ \\
\hline C57BL/6J & $21 \%(n=131)$ \\
B6;C3H (75 \% B6, 25\% C3H) & $10 \%{ }^{a}$ \\
$129 S v E v / 129 S v J$ & $28 \%{ }^{a}$ \\
Black Swiss/SvJ &
\end{tabular}


Table 2 Ratios of all genotypes in a Ts65Dn $\times$ Tb $\times 5^{+/-}$mating on a $\mathrm{B} 6 ; \mathrm{C} 3 \mathrm{H}(75 \% \mathrm{~B} 6,25 \% \mathrm{C} 3 \mathrm{H}$ background at P0

\begin{tabular}{|c|c|}
\hline Genotype & Number (\%), $n=180$ \\
\hline$\overline{T b \times 5^{+/+}}$ & $52(28.9 \%)$ \\
\hline$T b \times 5^{+/-}$ & $51(28.3 \%)$ \\
\hline Ts65Dn;Tbx $5^{+/+}$ & $46(25.6 \%)$ \\
\hline Ts65Dn;Tbx5 & $31(17.2 \%)$ \\
\hline
\end{tabular}

modifier of CHD. Genetic background of the Tbx5 mice affected viability (Table 1 and [20]). At birth, Tbx5 genotypes appeared at Mendelian ratios on a $\mathrm{B} 6 \times \mathrm{C} 3 \mathrm{H}(75 \%$ B6, $25 \% \mathrm{C} 3 \mathrm{H}$ ) background (Table 2), but by weaning, the frequency of the $T b \times 5^{+/-}$genotype was $21 \%$ rather than the expected $50 \%$. On a B6 background, the frequency of the $T b \times 5^{+/-}$genotype at weaning was $11 \%$. Thus, genetic factors appear to contribute to perinatal lethality associated with $T b x 5^{+/-}$.

We examined $T b x 5$ expression in hearts at E11.5 and confirmed the expected down-regulation in $T b \times 5$ heterozygous null mice (Fig. 1). The original characterization of these mice demonstrated Tbx 5 RNA levels substantially less than $50 \%$ at E8.5 [21], and the very low expression seen here at E11.5 reflects that difference, as well. Surprisingly, Tbx5 mRNA was also reduced in Ts65Dn. There may be an additive effect between the two conditions, as the measured levels of Tbx 5 mRNA were lower still in Ts65Dn; Tbx $\times 5^{+/-}$mice.
Trisomy affects patterns of CHD in $T b \times 5^{+/-}$mice

Progeny of the Ts65Dn $x T b \times 5^{+/-}$crosses were collected within hours of birth, prepared for histology and assessed for the presence of CHD. All animals examined for $\mathrm{CHD}$ were on the $\mathrm{B} 6 \times \mathrm{C} 3 \mathrm{H}(75 \% \mathrm{~B} 6,25 \% \mathrm{C} 3 \mathrm{H})$ background. There is some loss of Ts65Dn fetuses during late gestation and the observed frequency of $42 \%$ trisomic pups at P0 (Table 2) was in the expected range $[22,23] . ~ T b x 5^{+/-}$mice were recovered at Mendelian ratios within hours of birth. CHD is highly penetrant in $T b \times 5^{+/-}$mice and we saw only a slight overall increase in the percentage of heart defects when the null allele occurred on a trisomic background (Table 3 and Additional file 1: Table S1). However, the pattern of effects was altered significantly by trisomy.

We observed overriding aorta (OA) in $~ 58 \%$ of Ts65Dn; $\mathrm{Tbx}^{+/-}$mice but only $\sim 18 \%$ of $\mathrm{Tb} \times 5^{+/-}$, a significant difference (Table $3, \mathrm{p}=0.0004$ ). OA consists of a VSD and an improperly positioned aorta directly over the VSD (Fig. 2b). The penetrance of AVSD was somewhat elevated in Ts65Dn; $\mathrm{Tbx}^{+/-}$mice, with $\sim 19 \%$ affected by AVSD vs. $5 \%$ of $T b x 5^{+/-}$mice, although it did not reach formal statistical significance $(p=0.07)$. ASD and Gerbode's defect, an abnormal communication between the right atrium and left ventricle (Fig. 2c,d), were also seen more frequently in Ts65Dn; Tbx $5^{+/-}$but did not reach statistical significance. We performed CTbased Virtual Histology ${ }^{\mathrm{Tm}}$ on six Ts65Dn;Tbx $5^{+/-}$mice

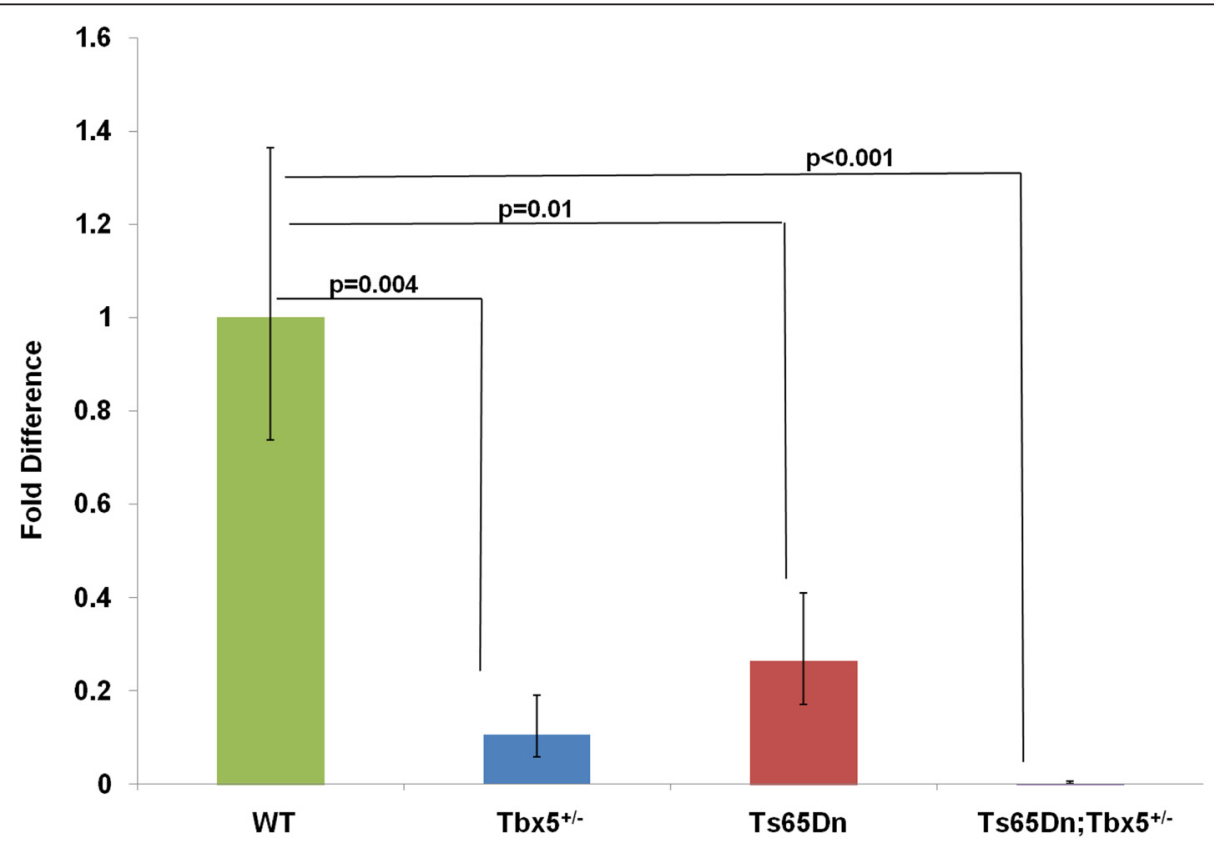

Fig. 1 Quantitative PCR of Tbx5 mRNA levels in pooled E11.5 hearts. mRNA expression was reduced to almost $10 \%$ of wild type levels in Tbx5 $5^{+/-}$ mice $(p=0.004)$. Note that previous studies found expression levels reduced to $20 \%$ of wild type levels in E8.5 Tbx $5^{+/-}$embryos on a mixed Black Swiss/129 background [21]. We found expression was also reduced to $30 \%$ of wild type levels in Ts65Dn mice $(p=0.01)$, and $2 \%$ of wild type levels in Ts65Dn;Tb $\times 5^{+/-}$hearts $(p<0.001)$. Error bars are standard deviation from the mean 
Table 3 CHDs in $\mathrm{Tb} 5^{+/-}$trisomic and euploid mice ${ }^{\mathrm{a}}$

\begin{tabular}{llllllll}
\hline Genotype & ASD & VSD only & Overriding Aorta & Gerbode's defect $^{b}$ & AVSD $^{c}$ & No defect & Total mice \\
\hline Tbx5 $^{+/-}$ & $11(27.5 \%)$ & $10(25 \%)$ & $7(17.5 \%)$ & $4(10 \%)$ & $2(5 \%)$ & $13(32.5 \%)$ & 40 \\
Ts65Dn; Tbx5 $^{+/-}$ & $12(38.7 \%)$ & $6(19.4 \%)$ & $18(58.1 \%)$ & $6(19.4 \%)$ & $6(19.4 \%)$ & $5(16 \%)$ & 31 \\
\hline
\end{tabular}

${ }^{a}$ Several animals had more than one defect. (see Additional file 1: Table S1)

${ }^{b}$ There is a significant difference between euploid and trisomic Tbx5 heterozygous mice in the occurrence of overriding aorta $(p=0.0004)$

${ }^{\mathrm{C}}$ The difference between euploid and trisomic Tbx5 heterozygous mice in AVSD is approaching significance $(p=0.07)$

(Numira Biosciences, Salt Lake City, UT; see Methods). Three of these animals were affected, with an AVSD, ASD and VSD, respectively (see Additional file 2: video 1, Additional file 3: video 2 and Additional file 4: video 3).

\section{Candidate trisomic gene interaction with $T b \times 5$}

The simplest explanation for the increased incidence of overriding aorta in Ts65Dn;Tbx $5^{+/-}$mice is an interaction between $T b x 5$ and a trisomic gene(s) that is regulated by this transcription factor. We considered 109 genes that are trisomic in Ts65Dn mice
[24] and generated a list of candidate trisomic genes based on expression patterns (Additional file 5: Figure S1). Sixty-four of these genes are expressed in the heart during development and 43 of them contained regions that associated with TBX5 in a ChIP study [25]. However, examination of the genomic sequences of these 43 revealed a T-box binding element (TBE) in only six (Adamts1, Dyrk1a, Rcan1, Ripply3, Sh3bgr and Wrb). We used the Transcription Element Search System program (TESS; see Methods) to identify potential TBEs in the first exons and/or promoter

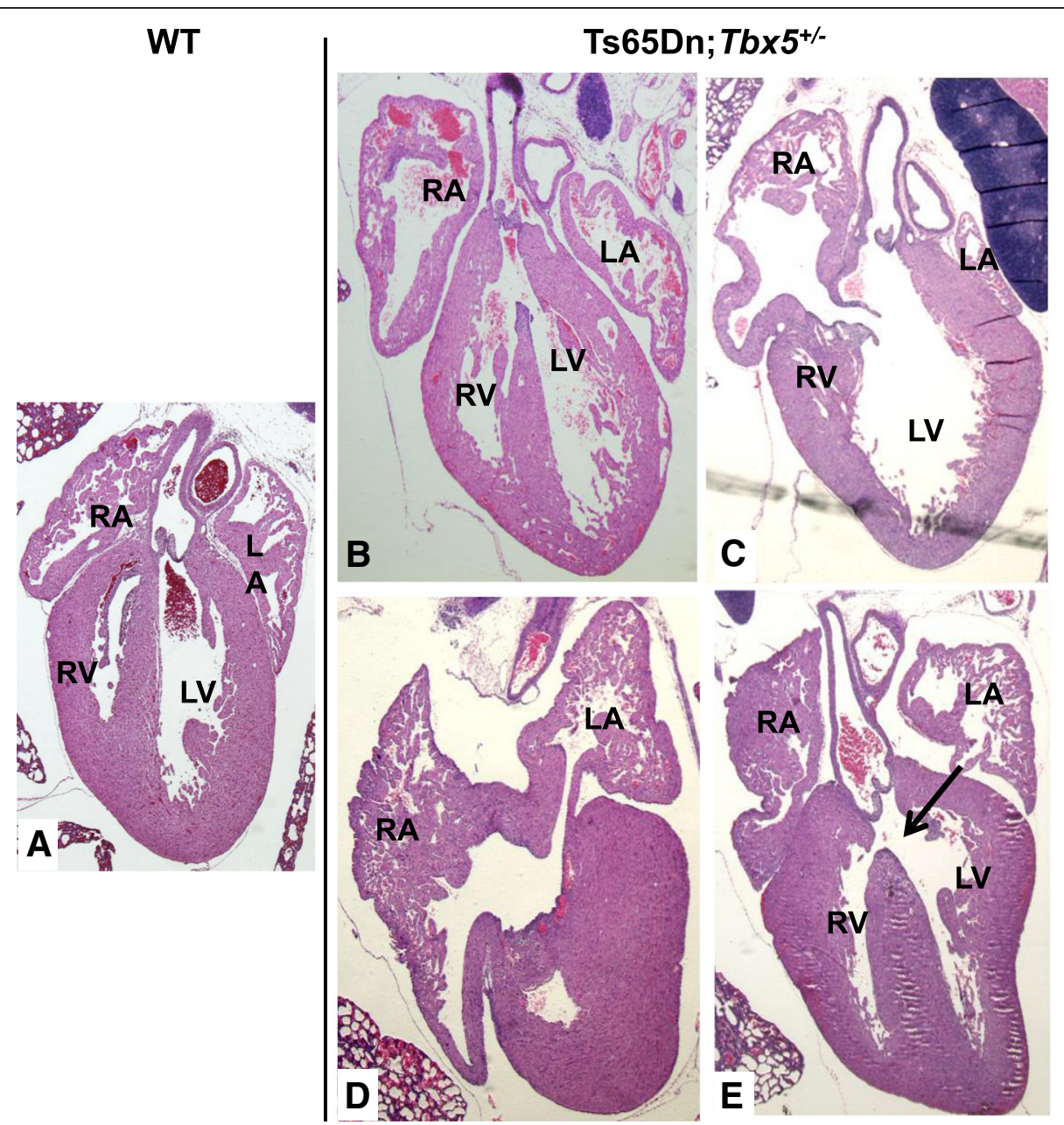

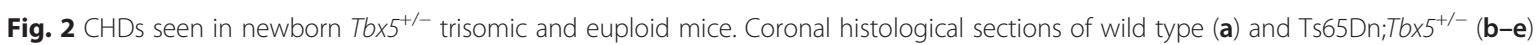
newborn mice stained with H\&E. Overriding aorta (b), Gerbode's defect (c), ASDs (d), and VSDs (e) were seen in the examined animals. RA/LA: right/left atrium, RV/LV: right/left ventricle 


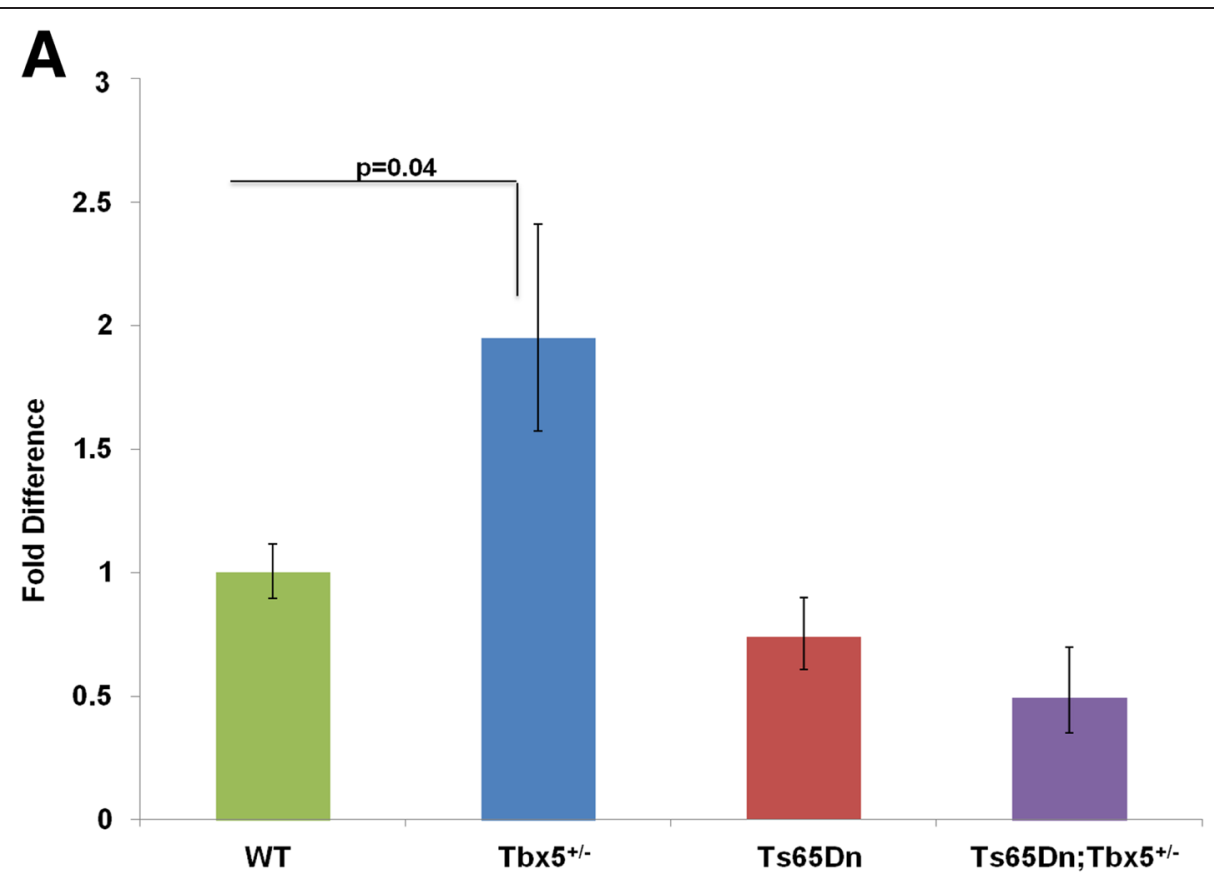

B

300

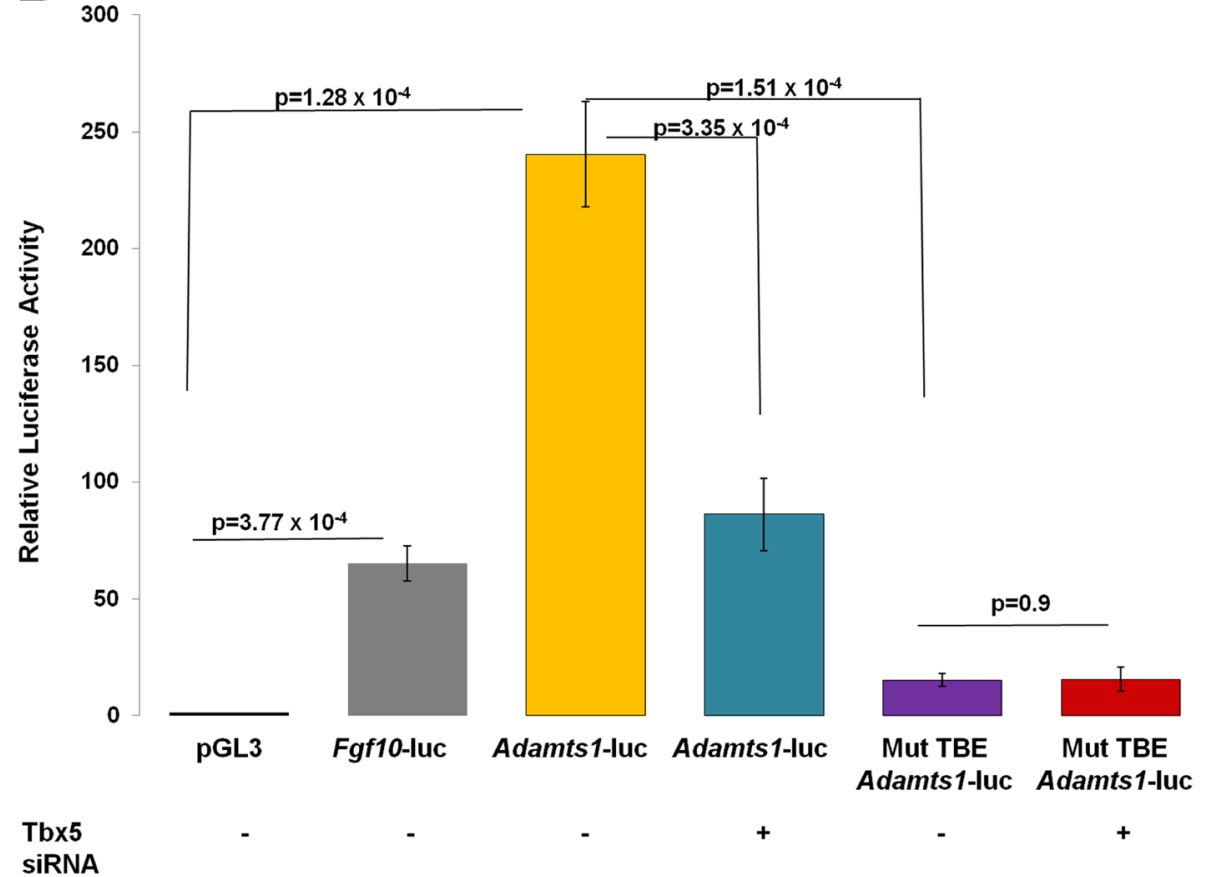

Fig. 3 Interaction between Tbx5 and trisomic gene, Adamts1. Quantitative PCR of Adamts1 mRNA levels in pooled E11.5 hearts (a). Adamts1 expression levels are significantly increased in euploid $T b \times 5^{+/}$mice $(1.95 x, p=0.04)$. No other changes were significant compared to the wild type expression. Error bars are standard deviation from the mean. TBX5 binding upstream of the Adamts 1 locus alters transcription (b). Cells

transfected with the Adamts7-luc construct showed increased luciferase when compared to the pGL3 construct $\left(p=1.28 \times 10^{-4}\right)$. Cells transfected with the Adamts1-luc construct and Tbx5 siRNA showed significantly lower luciferase levels when compared to those transfected with the Adamts 7 -luc construct alone ( $p=3.35 \times 10^{-4}$, compared to Adamts1-luc). Luciferase levels dropped significantly when the TBE was mutated to inhibit TBX5 binding $\left(p=1.51 \times 10^{-4}\right)$. Addition of Tbx5 siRNA did not affect transcription when the TBE was mutated $(p=0.9)$ Error bars are standard deviation. The region inserted into the basic $\mathrm{PGL} 3$ vector is $121 \mathrm{bp}$ upstream of the Adamts 1 gene, contains a putative TBE and associated with TBX5 in a ChIP study. Tbx5 over expressing cells were harvested $48 \mathrm{~h}$ after transfection. The FGF10-luciferase construct was used as a positive control. Graph represents one experiment representative of all replicates 
regions of those genes [26] (see Methods). Based on prior reports of possible effects on heart development, evolutionary conservation, the presence of TBEs and binding sites for other heart specific transcription factors, we selected Adamts1 for further investigation.

Adamts1 encodes an extracellular matrix protease. Transcript levels were increased in $T b \times 5^{+/-}$mice $(\mathrm{p}=0.04)$ (Fig. 3a), suggesting that $T b \times 5$ may act as a repressor of Adamts1. Using TESS, we found a putative TBE upstream of the Adamts1 locus and tested it using a luciferase reporter assay. The putative site, located 229 bp upstream of the Adamts1 transcription start site, was identical to the canonical TBE (RGGTGTVR) [27]. He et al. [25] found that this region is bound by TBX5 in a chromatin immunoprecipitation assay. A 238 bp region containing the putative site and located $121 \mathrm{bp}$ upstream of the Adamts1 transcription start site, was amplified by PCR and cloned into the pGL3 luciferase vector (Additional file 6: Figure S2).

We transfected the construct into cells stably over expressing Tbx5 (Additional file 7: Figure S3). Luciferase levels were increased in cells transfected with the Adamts1-luc construct compared to cells transfected with empty pGL3 vector $\left(\mathrm{p}=1.28 \times 10^{-4}\right)$ (Fig. 3b). Introduction of siRNA directed at $T b \times 5$ reduced this effect $\left(\mathrm{p}=3.35 \times 10^{-4}\right)$. The putative TBE was mutated to inhibit TBX5 binding and luciferase levels decreased compared to the construct with the intact $\mathrm{TBE}$ $\left(\mathrm{p}=1.51 \times 10^{-4}\right)$.

$T b \times 5$ is generally considered to be an inducer of transcription, consistent with the increase in luciferase signal when TBX5 binds the upstream Adamts1 region included in the construct. However, Adamts1 expression is increased when Tbx5 is reduced in $T b \times 5^{+/-}$mice (Fig. 3a). This discrepancy is likely due to the involvement of distal elements in transcriptional regulation that were not included in the construct and/or the lack of critical co-regulators in 3T3 cells. It is not surprising that in vivo results would differ in the presence of the entire promoter, as well as other transcription factors and co-regulators.

Atrial isomerism in Ts65Dn; $\mathrm{Tb} 5^{+/-}$mice

Overriding aorta and Gerbode's defect are seen more often in Ts65Dn; $T b \times 5^{+/-}$mice than in their $T b \times 5^{+/-}$littermates or euploid controls. We hypothesized that these might be accompanied by atrial isomerism. In this situation both atria are mirror images of one another and lack the typical morphological and molecular characteristics of either the right or left atrium. Normally, Pitx2 is specifically expressed in the left atrium and it is absent or ectopically expressed in the right atrium in cases of atrial isomerism [28]. To determine whether atrial isomerism occurred in Ts65Dn; $T b \times 5^{+/-}$mice, in situ hybridization for Pitx2 was performed on coronal paraffin sections of E13.5 thoraxes. Pitx2 expression can be seen in the left atrium of the heart in euploid embryos, but that expression is much weaker in the mutants (Fig. 4a,c). These results were confirmed by quantitative PCR of whole hearts from E13.5 embryos (Fig. 4e), where Pitx2 expression was reduced in Ts65Dn; $T b x 5^{+/-}$compared to euploid littermates $(\mathrm{p}=0.01)$. The expected expression pattern was observed in other organs (Additional file 8: Figure S4). The weak Pitx2 expression in the atria of Ts65Dn, $T b \times 5^{+/}$embryos suggests that these embryos have defects in laterality (i.e., atrial isomerism). Thus, atrial isomerism likely contributes to the significant increase in overriding aorta in the Ts65Dn;Tb $\times 5^{+/-}$animals.

\section{Discussion}

The interaction between $T b x 5$ dosage and trisomy resulted in a significant increase in defects of aortic alignment and revealed a potential effect on left-right patterning of the heart. The action of genetic modifiers in heart development is evident from the differences in penetrance and patterns of heart phenotypes in DS, in DS mouse models and when the Tbx5 null allele is bred onto different mouse genetic backgrounds. In addition, Holt-Oram patients who inherit the same TBX5 mutation have variable heart phenotypes, indicating that additional factors affect development [29]. Previous work from our lab and others has shown how interactions between trisomy and disomic modifier genes, both in humans and in mouse models, can adversely affect heart development $[8,9]$. For example, VEGF-A, HEY2 and the matricellular protein CRELD1 each have an impact, but they represent a small subset of genes in which variants contribute risk of CHD. Individuals with DS and mutations in TBX5 displaying OA and a number of additional defects have been described [30]. Isolated OA is not frequent in DS, however it is a component of Tetralogy of Fallot which occurs in 1-8 \% of DS births, far higher than in the population at large [2]. Our results demonstrate an interaction between altered $T b x 5$ expression and trisomy with increased $\mathrm{OA}$ as a primary outcome.

Disruptions in the left-right patterning pathway frequently lead to the kinds of heart defects seen here. OA is considered to be a milder form of double outlet right ventricle (DORV), the most common defect seen in Pitx2 knockout mice [31], arising in part due to aortic shifting [32]. Reducing the level of Pitx2 expression is sufficient to cause septal and valve defects [33]. Mice lacking the Pitx 2 and Cited 2 genes which are involved in left-right patterning exhibit phenotypes similar to the ones reported, including Gerbode's defect and overriding aorta [32-37]. Pitx2 is an important determinant of left- 

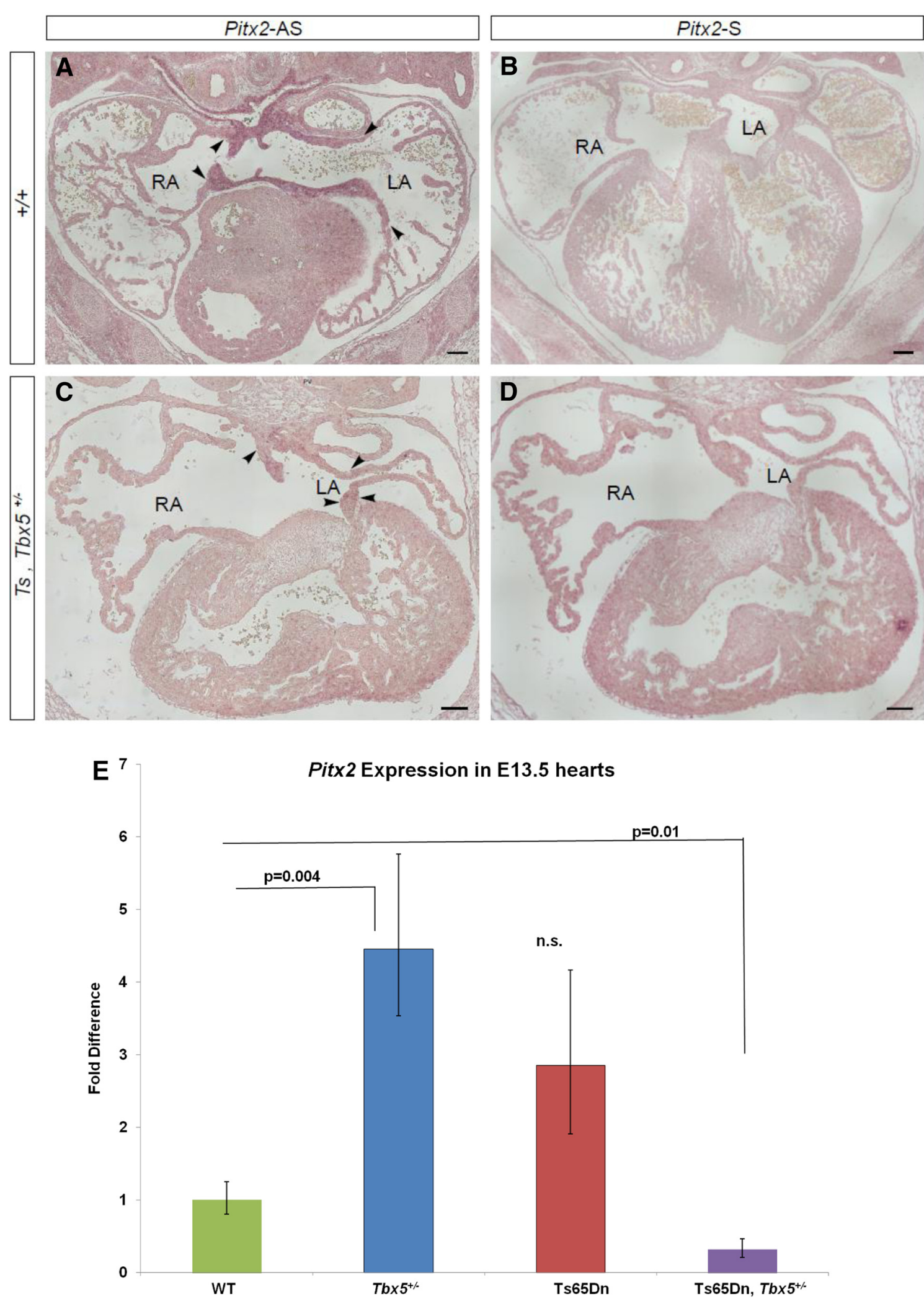

Fig. 4 (See legend on next page.) 
(See figure on previous page.)

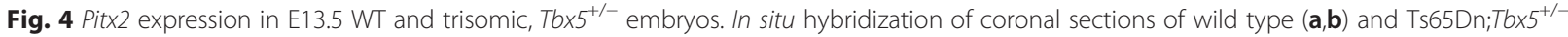
$(\mathbf{c}, \mathbf{d})$ mice. Pitx2 expression can be seen in the left atrium of the WT animals (a). Pitx2 expression is much weaker in the trisomic, Tbx $5^{+/-}$mutants (c). Scale bar equals to $100 \mu \mathrm{m}$. RA/LA: right/left atrium. In situ hybridization results were verified through quantitative PCR in E13.5 hearts (e). Error bars are standard deviation from the mean

right asymmetry of the heart and gut [28, 33, 37-40] and confers left atrial identity; its misexpression can result in atrial isomerism [28, 39, 41]. T-box family transcription factors are known to regulate Pitx2 expression [42], and Pitx 2 regulates Tbx5 expression in the abdominal wall during development [43]. Ts65Dn; Tb $x 5^{+/-}$embryos have reduced Pitx2 expression, which can contribute to atrial isomerism and aortic defects.

The left-right signaling pathway is affected when trisomy and $T b x 5$ haploinsufficiency are combined. We suggested previously that a universal response deficit to Sonic hedgehog signaling due to trisomy could explain many of the clinical features of DS [44]; hedgehog signaling plays a regulatory role in left-right patterning and can regulate Pitx2 expression [45-47]. Expression of Sonic hedgehog in the second heart field is essential for proper growth of the dorsal mesenchymal protrusion, without which AVSD occurs [48]. A response deficit to $\mathrm{SHH}$ in Ts65Dn could contribute to the altered localization of Pitx2 expression seen here.

Finally, we discovered that mice with reduced $T b x 5$ dosage show increased expression of the Adamts1 gene. Adamts1 is important in the development of the extracellular matrix in endocardial cushions [49], and is a regulator of the VEGF pathway [50]. It is interesting that individuals with DS who have an AVSD show an excess of deleterious variants in VEGF pathway genes relative to those with DS who do not have CHD [8]. Reduced Tbx5 dosage may contribute to the risk of heart defects by a role in transcriptional regulation of the Adamts1 gene, a regulator of the VEGF pathway.

Defects in left-right patterning likely contribute to the significant increase in overriding aorta in Ts65Dn; Tb $\times 5^{+/-}$ mice relative to either genetic defects in isolation. The mechanism likely involves reduced expression of Pitx2, a gene with known roles in laterality. In addition, we demonstrated that a change in $T b x 5$ dosage affects transcription of Adamts1, suggesting it is a target of TBX5 in normal heart development in vivo.

\section{Conclusions}

We have shown that $T b x 5$ dosage and trisomy interact to affect the outcome of heart development, potentially altering left-right patterning of the heart. We provided evidence of weak Pitx2 expression, important for leftright patterning, in the Ts65Dn; $T b \times 5^{+/-}$mice. We have also provided evidence that TBX5 plays a role in regulation of the trisomic Adamts1 gene. A valid TBX5 binding site was shown upstream of the Adamts1 locus and mutation of the site significantly affected transcription.

\section{Methods}

\section{Animal husbandry}

Animals were maintained in a virus and antibody-free facility with food and water ad libitum. Ts65Dn mice (B6EiC3H-a/A-Ts $\left.\left(17^{16}\right) 65 \mathrm{Dn}\right)$ were obtained from The Jackson Laboratory and maintained as an advanced intercross on the $\mathrm{B} 6 ; \mathrm{C} 3 \mathrm{H}$ background. $\mathrm{Tb} \times 5$ heterozygous null mice $\left(T b x 5^{+/-}\right)$[20] were kindly provided by Dr. Jonathan Seidman. We backcrossed the $T b \times 5^{+/-}$ mice onto a C57BL/6J background for at least five generations. All data was taken after mice had been backcrossed for at least five generations. Progeny in Tables 1 and 2 were the result of separate experiments. Progeny in Table 1 were obtained by crossing $T b x 5^{+/-}$mice on a B6 background with wild type B6 mice (obtained from Jackson Laboratory) or $\mathrm{B} 6 ; \mathrm{C} 3 \mathrm{H}$ mice bred in our lab. Progeny in Tables 2 and 3 were obtained at P0 via crosses between Ts65Dn females $(\mathrm{B} 6 ; \mathrm{C} 3 \mathrm{H})$ and $T b \times 5^{+/-}$males on a $\mathrm{B} 6$ background. All procedures were approved by the Institutional Animal Care and Use Committee.

\section{Genotyping}

We extracted genomic DNA from tail tips of mice by heating at $90{ }^{\circ} \mathrm{C}$ for $2 \mathrm{~h}$ in $10 \mathrm{mM} \mathrm{NaOH}, 0.2 \mathrm{mM}$ EDTA and used for genotyping by PCR. Sequences of primers for Ts65Dn genotyping are as follows: C17F: 5' GTGGCAAGAGACTCAAATTCAAC-3'; C16R: 5' -TG GCTTATTATTATCAGGGCATTT-3'; IMR5: 5'-AAA GTCGCTCTGAGTTGTTAT-3'; IMR6: 5'-GGAGCG GGAGAAATGGATATG-3'. For Ts65Dn genotyping, PCR was done under the following cycling conditions: $95{ }^{\circ} \mathrm{C} 3 \mathrm{~min},\left(94{ }^{\circ} \mathrm{C} 10 \mathrm{~s}, 58.7^{\circ} \mathrm{C} 20 \mathrm{~s}, 72{ }^{\circ} \mathrm{C} 27 \mathrm{~s}\right.$ ) for 31 cycles, $72{ }^{\circ} \mathrm{C} 5 \mathrm{~min}$. For $\mathrm{Tb} \times 5$ genotyping, three primers designed to amplify either the wild type or null alleles were added together in each reaction [20]. The sequences of the primers for $T b x 5$ genotyping are as follows: 3 F2: 5'-CCCAGCGGCAGGCGTAGAC -3'; Loxp-F: 5' -GCAGCGCAGTCCTCACCAG -3'; Loxp-R: 5'-AAATTCCAACCCCTTCCACAGAT -3'. The PCR was done under the following cycling conditions: $94{ }^{\circ} \mathrm{C}$ $3 \mathrm{~min},\left(94{ }^{\circ} \mathrm{C} 30 \mathrm{~s}, 59.7{ }^{\circ} \mathrm{C} \mathrm{30s,} 72^{\circ} \mathrm{C} 1 \mathrm{~min}\right)$ for 35 cycles, $72{ }^{\circ} \mathrm{C} 10 \mathrm{~min}$. 


\section{Histology}

We collected the progeny of Ts65Dn $\times \mathrm{Tb} \times 5^{+/-}$crosses at postnatal day 0 (P0) within hours of birth. We euthanized pups and removed and fixed thoraxes in $10 \%$ formalin for at least $48 \mathrm{~h}$. Tissues were embedded in paraffin, sectioned at $7 \mu \mathrm{m}$ and stained with hematoxylin/eosin using standard methods. The heart morphology in each animal was scored under a dissecting stereomicroscope (Nikon SMZ1500, Japan) by at least two individuals blinded to genotype. Pictures were taken using the NIS-Elements $\mathrm{Br}$ software (Nikon, Japan).

Virtual Histology ${ }^{\text {Tx }}$ was performed on six Ts65Dn;Tb $x 5^{+/-}$ mice (Numira Biosciences, Salt Lake City, UT). Virtual Histology $^{\text {тm }}$ is a micro-CT based method that allows for high resolution imaging. Specimens were stained in a proprietary solution before being scanned at $20 \mu \mathrm{m}$ resolution with a volumetric micro-CT instrument. Using this method tissues are left intact and imaging analysis can be used to create "virtual" histological sections.

\section{Identification of candidate genes}

We examined 109 genes that are trisomic in Ts65Dn mice for localization of expression in the heart using the following databases: EMAGE gene expression database [51], VisiGene image browser [52], the Chromosome 21 gene expression atlas [53], and the MGI gene expression database [54]. Trisomic genes expressed in heart during development, according to the above databases, were compared to a list of genes bound by TBX5 in a chromatin immunoprecipitation (ChIP) study [25]. We generated a list of trisomic candidate genes expressed in heart and bound by TBX5 (Additional file 5: Figure S1, Additional file 9: Table S2). From the list of 43 genes, we chose 6 as top candidates. The top 6 genes were the only genes out of the 43 which had a TBE in their promoter regions, were bound by other heart specific transcription factors, had high evolutionary conservation and were previously implicated in heart development. The Transcription Element Search System [26] was used to search for the TBE (RGGTGTVR) in regions of the 43 candidate genes that had a known or speculated role in heart development [27].

\section{Real-time analysis of gene expression}

We extracted total RNA from the hearts of embryos using the RNeasy mini kit (Qiagen, Venlo, Netherlands). cDNA synthesis was carried out with the First-Strand cDNA synthesis kit (Life Sciences Advanced Technologies, St. Petersburg, FL) using $1 \mu \mathrm{g}$ of total RNA as template. PCR was carried out on a 7500 Real-Time PCR System (Applied Biosystems, Carlsbad, CA). Tbx5 was quantified using a Taqman FAM-labeled pre-designed assay (Mm0195728_m1) from Applied Biosystems and normalized to a Gapdh VIClabeled assay (Mm99999915_g1) using Taqman Gene
Expression master mix. POWER SybrGreen master mix was used for all other expression assays (Applied Biosystems, Carlsbad, CA). Primers used are as follows: Adamts1F: 5' -CACGTGTGACACTCTCGGAA-3'; Adamts1-R: 5' CGTGCGGCATGTTAAACACA-3'; Gapdh-F: 5' -TGCA CCACCAACTGCTTAG-3'; Gapdh-R: 5' -GATGCAGGGATGATGTTC-3'; Pitx2-F: 5'-GCAGCCGTTGAATGT CTCTTC-3'; Pitx2-R: 5'-GTCCGTGAACTCGACCTTT TT-3'. PCR was done under the following cycling conditions: $95^{\circ} \mathrm{C} 15 \mathrm{~min},\left(95^{\circ} \mathrm{C} 15 \mathrm{~s}, 60^{\circ} \mathrm{C} 1 \mathrm{~min}\right)$ for 40 cycles, followed by a melt curve analysis between 95 and $60{ }^{\circ} \mathrm{C}$. Expression of candidate genes was normalized to Gapdh. Fold change expression values were determined using the delta delta Ct method [55].

\section{Creation of Tbx 5 constitutively over-expressing cells}

We obtained a $T b x 5$ cDNA clone from the I.M.A.G.E. consortium and subcloned it into the pcDNA3.1+ vector (Life Technologies, Carlsbad, CA), putting it under the control of the CMV promoter. NIH-3T3 cells were transfected with the pcDNA-Tbx5 construct using Lipofectamine 2000 (Life Technologies, Carlsbad, CA). Stably transfected cell lines were selected with $1 \mathrm{mg} /$ ml Geneticin (Gibco, Carlsbad, CA). We maintained the cells in Dulbecco's Modified Eagle Medium with high glucose $(4.5 \mathrm{~g} / \mathrm{L})$ (Life Technologies, Carlsbad, CA), $10 \%$ fetal bovine serum, $1 \mathrm{mg} / \mathrm{ml}$ Geneticin, $1 \mathrm{X}$ glutamine and penicillin/streptomycin at $37{ }^{\circ} \mathrm{C}$ and $5 \% \mathrm{CO}_{2}$.

\section{Functional studies and luciferase assay}

We amplified the portion of the promoter region of Adamts1 that was bound by TBX5 in a ChIP study [25], by PCR with the insertion of cut sites for KpnI and Xhol. PCR primers are as follows, F: 5'-GGCGCTTATGGTACCTGGTCACACTTTTTTTGG-3'; R: 5'- GGCGCTTATCTCGAGCACCTTCACAGAGGCTCA-3'. The amplified region was subcloned into the pGL3 basic vector (Promega, Madison, WI). Site directed mutagenesis was used to mutate the putative TBE site found upstream of the Adamts1 promoter. The following primers were used to mutate the putative TBE site and insert an EcoRI restriction site, Primer 1: 5' -CACAGCTCGTCACTCTGGGAATTCAAGA CGCCGAAACAGCGCTG-3'; Primer 2: 5'-CAGCGC TGTTTCGGCGTCTTGAATTCCCAGAGTGACGAGC TGTG-3'. We transfected the constructs into NIH-3T3 cells constitutively over expressing Tbx5 (Additional file 7: Figure S3). Tbx5 siRNA and scrambled siRNA were purchased from Life Technologies (Carlsbad,CA). Luciferase levels were measured in a 1450 Wallac Jet MicroBeta liquid scintillation and luminescence counter (Perkin-Elmer, Waltham, MA) using the Dual Luciferase Assay Kit (Promega, Madison, WI). 


\section{In Situ hybridization}

E13.5 embryos were fixed in $4 \%$ paraformaldehyde for $1 \mathrm{~h}$, rinsed in $1 \mathrm{X}$ PBS three times for $5 \mathrm{~min}$ and then dehydrated in 25, 50 and $70 \%$ ethanol for $1 \mathrm{~h}$ each. After dehydration the embryos were stored at $-20{ }^{\circ} \mathrm{C}$ in $70 \%$ ethanol until embedded in paraffin and sectioned according to standard methods. We performed in situ hybridization using traditional dioxigenin (DIG)-labeled RNA probes detected with alkaline phoshatase (AP)conjugated anti-dioxigenin antibody using nitro blue tetrazolium chloride / 5-bromo-4-chloro-3-indolyl-phosphate toluidine-salt (NBT/BCIP) substrate. DIG RNA labeling mix, anti-DIG-AP antibody, blocking reagent, NBT/ BCIP were all purchased from Roche Applied Science (Indianapolis, IN) and used according to the manufacturer's instructions with minimal modifications. The Pitx2 antisense and sense probes were described earlier [56]. Images were taken with the Leica DMRB upright light microscope using the Leica Application Suite Software v4.3 (Leica Microsystems-W. Nuhsbaum Inc., McHenry, IL). Composite images were compiled using Adobe Illustrator CS4 (Adobe Systems, San Jose, CA).

\section{Statistical analysis}

The incidence of various heart defects for different genotypes was compared by Fisher's test using GraphPad Prism version 5 . A $2 \times 2$ contingency table was made comparing the two groups for each separate phenotype. The relative quantification of gene expression from different genotypes was compared by the student's $t$-test using delta Ct values. All tests were 2-tailed and $\mathrm{P}<0.05$ were considered significant.

\section{Additional files}

Additional file 1: Video 1. https://jh.box.com/s/z3o7797mxgmiw5ow bxcrey78069y2tir. VSD in a Ts65Dn; Tbx $5^{+/-} \mathrm{PO}$ animal. 3D rendering of the heart of a P0 Ts65Dn; Tb $\times 5^{+/-}$depicting a VSD. At the start of the video a coronal view of the heart can be seen. The left and right atria as well as the ventricles are shown. The heart then rotates so the view is now transverse. In the transverse view the heart is slowly cut away revealing the interior ventricles and a ventricular septal defect.

Additional file 2: Video 2. https://jh.box.com/s/3peeo5dazhdkil23ffx b62xblloybsnk. ASD in a Ts65Dn; Tbx $5^{+/-} \mathrm{P0}$ animal. 3D rendering of the heart of a P0 Ts65Dn; Tbx $5^{+/-}$depicting an ASD. At the start of the video a coronal view of the heart can be seen. The left and right atria as well as the ventricles are shown. The heart rotates to a sagittal view. The heart is then slowly cut away revealing the interior of the right atria and an atrial septal defect.

Additional file 3: Video 3. https://jh.box.com/s/2loh3n0x55hbmstcu $4 \mathrm{kxn} 9 \mathrm{rxt} 3 \mathrm{tmf} 2 \times 6$. AVSD in a Ts65Dn; Tbx $5^{+/-} \mathrm{PO}$ animal. CT scan of a P0 Ts65Dn; Tb $\times 5^{+/-}$depicting an AVSD. The video gives a coronal view of data collected during a micro-CT scan. The first look at the heart can be seen at 00:05. The video cuts away to reveal an atrioventricular septal defect in the heart, most clearly seen at 00:16.

Additional file 4: Figure S1. Identifying trisomic gene candidates for Tbx5 interaction. Gene expression databases were searched to find expression domains of all Ts65Dn trisomic genes. Genes that were expressed in the heart during development were further investigated for interaction with TBX5 in a ChIP study.

Additional file 5: Figure S2. Region of Adamts 1 gene inserted into $\mathrm{pGL3}$ vector. The $238 \mathrm{bp}$ region highlighted in gray contains the canonical T-box binding site (RGGTGTVR) and was amplified by PCR and cloned into a pGL3 luciferase vector (Promega). This region was associated with TBX5 in a ChIP study. The TBE is located $229 \mathrm{bp}$ upstream of the Adamts1 transcription start site.

Additional file 6: Figure S3. Tbx 5 mRNA expression in transfected cells. Quantitative PCR was used to measure Tbx5 expression in NIH-3T3 cells transfected with a Tbx5-pcDNA3.1+ construct using Lipofectamine 2000 (Life Technologies, Carlsbad, CA). Stably transfected cells expressed about 70 times as much Tbx5 as the NIH-3T3 cells. Stably transfected cell lines were selected with $1 \mathrm{mg} / \mathrm{ml}$ Geneticin (Gibco, Carlsbad, CA).

Additional file 7: Figure S4. Expression of Pitx2 with in situ hybridization (ISH) in E13.5 WT and trisomic, $\mathrm{Tb}^{+} 5^{+/-}$mutants in other areas as pituitary $(A, E, I, M)$, tooth bud $(B, F, J, N)$, and midbrain $(C, G, K$, $O)$ in sagittal sections and spinal cord in horizontal sections $(D, H, L, P)$. Embryo faces to the right in sagittal sections. Sections come from same animals as used for the heart studies and processed for ISH at the same time. Spinal cord photos are from the exact same slides photographed for heart studies. Arrowheads in Panel D and E mark expected Pitx2 staining in spinal cord neurons. Pitx2-AS: Pitx2 antisense probe, Pit×2S: Pitx2 sense probe. Scale bar equals to $100 \mu \mathrm{m}$.

Additional file 8: Table S1. Number of animals with multiple defects Additional file 9: Table S2. Forty-three Ts65Dn trisomic genes expressed in heart during development and bound by TBX5 in a ChIP experiment.

\section{Abbreviations}

DS: Down syndrome; CHD: Congenital heart defect; Hsa21: Human chromosome 21; AVSD: Atrioventricular septal defect; ASD: Atrial septal defect; VSD: Ventricular septal defect; LV: Left ventricle; RV: Right ventricle; Mmu16: Mouse chromosome 16; Mmu10: Mouse chromosome 10; Mmu17: Mouse chromosome 17; OA: Overriding aorta; ChIP: Chromatin immunoprecipitation; TBE: T-box binding element.

\section{Competing interests}

The authors declare that they have no competing interests.

\section{Authors' contributions}

RP designed and performed most experiments, analyzed data and drafted manuscript. In situ hybridization was performed by PG. HL, RP and JS also examined slides for mouse phenotyping. SAC and RHR designed the study. SAC, IM and RHR participated in study coordination. RHR helped to draft the manuscript and all authors participated in critical revision of the manuscript. All authors read and approved the final manuscript.

\section{Authors' information}

RHR is a scientific advisor to Roche Pharmaceuticals and to Elan Pharmaceuticals. Neither of these relationships involves the work described here.

\section{Acknowledgements}

We thank Dr. Valerie DeLeon for expert advice concerning phenotyping This work was supported in part by Award Number R01HL083300 from the National Heart, Lung and Blood Institute and by R01HD038384 from the EKS National Child Health and Human Development Institute (RHR), R01 HL124836 from the National Heart, Lung and Blood Institute (IM and RHR) and R01 HD34283 (SAC). Peter Gergics is a participant of the International Endocrine Scholars Program of The Endocrine Society. The content is solely the responsibility of the authors and does not necessarily represent the official views of the National Institutes of Health.

\section{Author details}

'Department of Physiology at Johns Hopkins, Biophysics 201, 725 N. Wolfe St., Baltimore, MD 21205, USA. ${ }^{2}$ McKusick Nathans Institute for Genetic Medicine, School of Medicine, Johns Hopkins University, Baltimore, MD, USA. ${ }^{3}$ Departments of Pediatrics, Pathology and Human Genetics, University of 
Chicago, Chicago, IL, USA. ${ }^{4}$ Department of Human Genetics, School of Medicine, University of Michigan, Ann Arbor, MI, USA.

\section{Received: 6 February 2015 Accepted: 7 July 2015} Published online: 25 July 2015

\section{References}

1. Rosamond W, Flegal K, Friday G, Furie K, Go A, Greenlund K, et al. Heart disease and stroke statistics - 2007 update - a report from the American Heart Association Statistics Committee and Stroke Statistics Subcommittee. Circulation. 2007;115(5):E69-E171.

2. Freeman SB, Taft LF, Dooley KJ, Allran K, Sherman SL, Hassold TJ, et al. Population-based study of congenital heart defects in Down syndrome. Am J Med Genet. 1998;80(3):213-7.

3. Ferencz C, Neill CA, Boughman JA, Rubin JD, Brenner JI, Perry LW. Congenital cardiovascular malformations associated with chromosome abnormalities: an epidemiologic study. J Pediatr. 1989;114(1):79-86.

4. Stoll C, Alembik Y, Dott B, Roth MP. Epidemiology of Down syndrome in 118,265 consecutive births. Am J Med Genet Suppl. 1990;7:79-83.

5. Khoury MJ, Erickson JD. Improved ascertainment of cardiovascular malformations in infants with Down's syndrome, Atlanta, 1968 through 1989. Implications for the interpretation of increasing rates of cardiovascular malformations in surveillance systems. Am J Epidemiol. 1992:136(12):1457-64

6. Wells GL, Barker SE, Finley SC, Colvin EV, Finley WH. Congenital heart disease in infants with Down's syndrome. South Med J. 1994;87(7):724-7.

7. Pradat P. Epidemiology of major congenital heart defects in Sweden 1981-1986. J Epidemiol Community Health. 1992:46(3):211-5.

8. Ackerman C, Locke AE, Feingold E, Reshey B, Espana K, Thusberg J, et al. An excess of deleterious variants in VEGF-a pathway genes in down-syndromeassociated atrioventricular septal defects. Am J Hum Genet. 2012;91(4):646-59.

9. Li H, Cherry S, Klinedinst D, DeLeon V, Redig J, Reshey B, et al. Genetic modifiers predisposing to congenital heart disease in the sensitized Down syndrome population. Circ Cardiovasc Genet. 2012:5(3):301-8.

10. Basson CT, Bachinsky DR, Lin RC, Levi T, Elkins JA, Soults J, et al. Mutations in human TBX5 [corrected] cause limb and cardiac malformation in Holt-Oram syndrome. Nat Genet. 1997;15(1):30-5.

11. Li QY, Newbury-Ecob RA, Terrett JA, Wilson DI, Curtis AR, Yi CH, et al. Holt-Oram syndrome is caused by mutations in TBX5, a member of the Brachyury (T) gene family. Nature genetics. 1997;15(1):21-9.

12. Newbury-Ecob RA, Leanage R, Raeburn JA, Young ID. Holt-Oram syndrome: a clinical genetic study. J Med Genet. 1996;33(4):300-7.

13. Bruneau BG, Logan M, Davis N, Levi T, Tabin CJ, Seidman JG, et al. Chamber-specific cardiac expression of Tbx5 and heart defects in Holt-Oram syndrome. Developmental Biology. 1999;211(1):100-8.

14. Koshiba-Takeuchi K, Mori AD, Kaynak BL, Cebra-Thomas J, Sukonnik T, Georges RO, et al. Reptilian heart development and the molecular basis of cardiac chamber evolution. Nature. 2009;461(7260):95-8.

15. Moore CS, Roper RJ. The power of comparative and developmental studies for mouse models of Down syndrome. Mammalian Genome. 2007;18(6-7):431-43.

16. Reeves RH, Irving NG, Moran TH, Wohn A, Kitt C, Sisodia SS, et al. A mouse model for Down syndrome exhibits learning and behaviour deficits. Nat Genet. 1995;11(2):177-84

17. Reinholdt L, Ding Y, Gilbert GJ, Czechanski A, Solzak JP, Roper RJ, et al. Molecular characterization of the translocation breakpoints in the Down syndrome mouse model Ts65Dn. Mamm Genome. 2011;22(11-12):685-91.

18. Duchon A, Raveau M, Chevalier C, Nalesso V, Sharp AJ, Herault Y. Identification of the translocation breakpoints in the Ts65Dn and Ts1Cje mouse lines: relevance for modeling Down syndrome. Mamm Genome. 2011:22(11-12):674-84

19. Williams AD, Mjaatvedt $\mathrm{CH}$, Moore CS. Characterization of the cardiac phenotype in neonatal Ts65Dn mice. Dev Dyn. 2008;237(2):426-35.

20. Bruneau BG, Nemer G, Schmitt JP, Charron F, Robitaille L, Caron S, et al. A murine model of Holt-Oram syndrome defines roles of the T-box transcription factor Tbx5 in cardiogenesis and disease. Cell. 2001;106(6):709-21.

21. Mori AD, Zhu Y, Vahora I, Nieman B, Koshiba-Takeuchi K, Davidson $L$, et al. Tbx5-dependent rheostatic control of cardiac gene expression and morphogenesis. Developmental Biology. 2006;297(2):566-86.
22. Moore CS. Postnatal lethality and cardiac anomalies in the Ts65Dn Down syndrome mouse model. Mamm Genome. 2006;17(10):1005-12.

23. Roper RJ, St John HK, Philip J, Lawler A, Reeves RH. Perinatal loss of Ts65Dn Down syndrome mice. Genetics. 2006;172(1):437-43.

24. Starbuck JM, Dutka T, Ratliff TS, Reeves RH, Richtsmeier JT. Overlapping trisomies for human chromosome 21 orthologs produce similar effects on skull and brain morphology of Dp(16)1Yey and Ts65Dn mice. Am J Med Genet A. 2014:164A(8):1981-90.

25. He A, Kong SW, Ma Q, Pu WT. Co-occupancy by multiple cardiac transcription factors identifies transcriptional enhancers active in heart. Proc Natl Acad Sci U S A. 2011;108(14):5632-7.

26. Schug J. Using TESS to predict transcription factor binding sites in DNA sequence. Curr Protoc Bioinformatics. 2008; Chapter 2:Unit 26.

27. Ghosh TK, Packham EA, Bonser AJ, Robinson TE, Cross SJ, Brook JD. Characterization of the TBX5 binding site and analysis of mutations that cause Holt-Oram syndrome. Human molecular genetics. 2001;10(18):1983-94

28. Ammirabile G, Tessari A, Pignataro V, Szumska D, Sutera Sardo F, Benes Jr J, et al. Pitx2 confers left morphological, molecular and functional identity to the sinus venosus myocardium. Cardiovasc Res. 2012;93(2):291-301.

29. Cross SJ, Ching YH, Li QY, Armstrong-Buisseret L, Spranger S, Lyonnet S, et al. The mutation spectrum in Holt-Oram syndrome. J Med Genet. 2000;37(10):785-7.

30. Reamon-Buettner SM, Borlak J. TBX5 mutations in non-Holt-Oram syndrome (HOS) malformed hearts. Human mutation. 2004;24(1):104-4.

31. Neeb Z, Lajiness JD, Bolanis E, Conway SJ. Cardiac outflow tract anomalies. Wiley Interdiscip Rev Dev Biol. 2013;2(4):499-530.

32. Lu MF, Pressman C, Dyer R, Johnson RL, Martin JF. Function of Rieger syndrome gene in left-right asymmetry and craniofacial development. Nature. 1999:401(6750):276-8

33. Gage PJ, Suh H, Camper SA. Dosage requirement of Pitx2 for development of multiple organs. Development. 1999:126(20):4643-51.

34. Franco D, Campione M. The role of Pitx2 during cardiac development. Linking left-right signaling and congenital heart diseases. Trends Cardiovasc Med. 2003;13(4):157-63.

35. Ai D, Liu W, Ma L, Dong F, Lu MF, Wang D, et al. Pitx2 regulates cardiac left-right asymmetry by patterning second cardiac lineage-derived myocardium. Dev Biol. 2006;296(2):437-49.

36. Lin CR, Kioussi C, O'Connell S, Briata P, Szeto D, Liu F, et al. Pitx2 regulates lung asymmetry, cardiac positioning and pituitary and tooth morphogenesis. Nature. 1999;401(6750):279-82.

37. Kitamura K, Miura H, Miyagawa-Tomita S, Yanazawa M, Katoh-Fukui Y, Suzuki $R$, et al. Mouse Pitx2 deficiency leads to anomalies of the ventral body wall, heart, extra- and periocular mesoderm and right pulmonary isomerism. Development. 1999;126(24):5749-58.

38. Ryan AK, Blumberg B, Rodriguez-Esteban C, Yonei-Tamura S, Tamura K, Tsukui T, et al. Pitx2 determines left-right asymmetry of internal organs in vertebrates. Nature. 1998:394(6693):545-51.

39. Campione M, Ros MA, Icardo JM, Piedra E, Christoffels VM, Schweickert A, et al. Pitx2 expression defines a left cardiac lineage of cells: evidence for atrial and ventricular molecular isomerism in the iv/iv mice. Dev Biol. 2001:231(1):252-64.

40. Liu C, Liu W, Lu MF, Brown NA, Martin JF. Regulation of left-right asymmetry by thresholds of Pitx2C activity. Development. 2001;128(11):2039-48.

41. Shiratori $\mathrm{H}$, Yashiro $\mathrm{K}$, Shen MM, Hamada $\mathrm{H}$. Conserved regulation and role of Pitx2 in situs-specific morphogenesis of visceral organs. Development. 2006;133(15):3015-25.

42. Nowotschin S, Liao J, Gage PJ, Epstein JA, Campione M, Morrow BE. Tbx affects asymmetric cardiac morphogenesis by regulating Pitx2 in the secondary heart field. Development. 2006;133(8):1565-73.

43. Hilton T, Gross MK, Kioussi C. Pitx2-dependent occupancy by histone deacetylases is associated with T-box gene regulation in mammalian abdominal tissue. J Biol Chem. 2010;285(15):11129-42.

44. Currier DG, Polk RC, Reeves RH. A Sonic hedgehog (Shh) response deficit in trisomic cells may be a common denominator for multiple features of Down syndrome. Prog Brain Res. 2012;197:223-36.

45. Zhang XM, Ramalho-Santos M, McMahon AP. Smoothened mutants reveal redundant roles for Shh and Ihh signaling including regulation of $L / R$ asymmetry by the mouse node. Cell. 2001;105(6):781-92. 
46. Logan M, Pagán-Westphal SM, Smith DM, Paganessi L, Tabin CJ. The transcription factor Pitx2 mediates situs-specific morphogenesis in response to left-right asymmetric signals. Cell. 1998;94(3):307-17.

47. Tsukui T, Capdevila J, Tamura K, Ruiz-Lozano P, Rodriguez-Esteban C, Yonei-Tamura S, et al. Multiple left-right asymmetry defects in Shh(-/-) mutant mice unveil a convergence of the shh and retinoic acid pathways in the control of Lefty-1. Proc Natl Acad Sci U S A. 1999;96(20):11376-81.

48. Hoffmann AD, Peterson MA, Friedland-Little JM, Anderson SA, Moskowitz IP. Sonic hedgehog is required in pulmonary endoderm for atrial septation. Development. 2009;136(10):1761-70

49. Kern CB, Twal WO, Mjaatvedt CH, Fairey SE, Toole BP, Iruela-Arispe ML, et al. Proteolytic cleavage of versican during cardiac cushion morphogenesis. Dev Dyn. 2006:235(8):2238-47.

50. Luque A, Carpizo DR, Iruela-Arispe ML. ADAMTS1/METH1 inhibits endothelial cell proliferation by direct binding and sequestration of VEGF165. J Biol Chem. 2003;278(26):23656-65.

51. Richardson L, Stevenson P, Venkataraman S, Yang Y, Burton N, Rao J, et al. EMAGE: electronic mouse atlas of gene expression. Methods Mol Biol. 2014;1092:61-79

52. Kuhn RM, Karolchik D, Zweig AS, Trumbower H, Thomas DJ, Thakkapallayil A, et al. The UCSC genome browser database: update 2007. Nucleic Acids Res. 2007:35(Database issue):D668-73.

53. Reymond A, Marigo V, Yaylaoglu MB, Leoni A, Ucla C, Scamuffa N, et al. Human chromosome 21 gene expression atlas in the mouse. Nature. 2002;420(6915):582-6.

54. Smith CM, Finger JH, Hayamizu TF, McCright IJ, Xu J, Eppig JT, et al. GXD: a community resource of mouse Gene Expression Data. Mammalian Genome. 2015. doi:10.1007/s00335-015-9563-1

55. Livak KJ, Schmittgen TD. Analysis of relative gene expression data using real-time quantitative PCR and the 2(-Delta Delta C(T)) Method. Methods. 2001;25(4):402-8.

56. Martin DM, Skidmore JM, Fox SE, Gage PJ, Camper SA. Pitx2 distinguishes subtypes of terminally differentiated neurons in the developing mouse neuroepithelium. Dev Biol. 2002;252(1):84-99.

\section{Submit your next manuscript to BioMed Central and take full advantage of:}

- Convenient online submission

- Thorough peer review

- No space constraints or color figure charges

- Immediate publication on acceptance

- Inclusion in PubMed, CAS, Scopus and Google Scholar

- Research which is freely available for redistribution 